\title{
Filosofia e literatura nas Afinidades Eletivas de Goethe
}

\author{
Arlenice Almeida da Silva - Unifesp
}

No final do século XVIII e início do século XIX o romance não para de se reinventar, exibindo plasticidade e grande liberdade formal; no entanto, ele é, ainda, grosso modo, um gênero narrativo. Cabe examinar, então, o que muda quando elementos não narrativos são introduzidos no romance, tais como diálogos filosóficos, dissertações, argumentos, ou máximas e reflexões, como as do Diário de Ottilie, em As afinidades eletivas, de Goethe. Como deve ser lido esse Diário? Via de regra, costuma ser lido como função estilística retardante, como pausa no ritmo narrativo ou modo de preparação do leitor para o desfecho fatídico.

Um dos desafios que o romance de Goethe propõe ao comentador é o de dimensionar o alcance de um pensamento que se expõe ao modo narrativo, tarefa que pressupõe, como primeiro passo, o exame da coexistência interna desses dois discursos, o dissertativo e o narrativo. Do Diário de Ottilie sabemos duas coisas aparentemente paradoxais: de um lado, ele é composto por fragmentos, máximas escolhidas ou recolhidas, bastante gerais, 
que não brotaram da própria reflexão pessoal da personagem, como usualmente ocorria no romance epistolar ou no romance de memórias - gêneros constitutivamente reflexivos - já que são apontamentos que foram copiados, provavelmente, diz o narrador, de um caderno qualquer (irgendeinen Heft) (Goethe, 2014, p. 187). Por outro lado, são ponderações que indiciam intensa subjetividade e uma particular organicidade, já que, nas palavras do autor, são anotações perpassadas por um fio vermelho que é "um fio de afeição e apego que tudo liga, assinalando-lhe a totalidade" (Ibid., p. 169); de modo que "pode-se reconhecer o fio vermelho em alguns aspectos relacionados a sua intimidade"(Ibid., p. 187).

Pode-se observar, além disso, que o Diário surge na segunda parte da obra, quando a jovem sofre tremendamente e, como é usual em Goethe, esse sofrimento não pode ser narrado: "não nos aventuramos aqui a descrever sua dor e suas lágrimas. Seu sofrimento não tinha fim" (Ibid., p. 142). Para os leitores de Goethe, esse interdito narrativo não causa surpresa, já que o mesmo foi dito a propósito do sofrimento de Charlotte, nas últimas linhas do Werther; em ambos, eles correspondem a momentos intensamente líricos das obras, sobre os quais Goethe justificara na Máxima 1121, encontrada em seu espólio, alegando que "a arte não deve representar o que é penoso.” (Goethe, 2001, p. 215)

Se o sofrimento como intensidade irredutível não pode ser descrito, Goethe sugere, no entanto, que ele, indiretamente, possa ser vertido em filosofia, ensejando um juízo ou uma reflexão. Certamente Ottilie não é filósofa e o problema de escritura para o romancista não é o de constituir uma personagem reflexiva apta a encarnar e apresentar um conteúdo filosófico explícito. No entanto, o Diário de Ottilie participa a seu modo do topos 
da mulher sábia ou das modalidades da mulher sábia do século XVIII. Vale observar, de passagem, que desde Thérèse philosophe, atribuído a Jean-Baptiste Boyer d'Argens, de 1748, ou La Filosofessa italiana, de Pietro Chiari, de 1753, até Justine, ou os infortúnios da virtude, de 1791, com o marquês de Sade, ocorrem na ficção deslocamentos nas modalidades tradicionais de enunciação da filosofia; nessas obras se abrem possibilidades para a constituição de novos lugares nos quais é possível narrar o aprendizado intelectual feminino, que em muitos casos é, ao mesmo tempo, filosófico e sexual. ${ }^{1}$ Nessa direção, as anotações de Ottilie indiciam certamente uma reflexão imatura, de uma jovem dotada de senso comum, ou senso prático; mesmo assim, correspondem a este topos ou lugar literário ocupado pela mulher que pensa com autonomia. Várias indicações apresentadas já no início do romance vão nessa direção: lemos, por exemplo, no anexo escrito pelo assistente da diretora, sobre as aptidões de Ottilie que, na escola, ela não aprende como alguém que precisa ser educada, mas como quem pretende educar; e que tem uma grande facilidade em estabelecer conexões, em buscar nexos. Por outro lado, em alguns poucos momentos, dada sua natureza silenciosa, ela surpreende os amigos com idéias e opiniões, quase sempre demasiadamente sensatas; além de bela, pura e boa, todos concordam, nesses momentos, que "Ottilie tem razão". Ou seja, entre os silêncios e a passividade, desponta, aqui e acolá, intenções de pensamento. Assim, é a única no grupo de amigos que tem simultaneamente capacidade expressiva e consciência da ideia do belo; a figura de Ottilie era, por exem-

${ }^{1}$ Cf. Florence Lotterie. "Comment la 'femme philosophe' peut-elle devenir personnage de Roman? Pour um bilan critique de la question". In: Fictions de La pensée, pensées de la fiction. Roman et philosophie aux XVII e XVIII siècles. Paris: Hermann Ėditeurs, 2013. p. 177-193. 
plo, nos quadros vivos, passatempo social em moda, a mais bela pois "exprimia assim tanto os próprios sentimentos quanto a ideia que se podia fazer daquilo que representava" (Goethe, 2014, p. 211).

Ottilie assemelhar-se-ia, assim, a um tipo fixado no romance da época de uma mulher sábia e, ao mesmo tempo, trágica, prisioneira do infortúnio: favorável à autonomia, mas derrotada pelo destino; situação paradoxal que, de um lado, a marginaliza e a silencia; de outro, ao contrário, lhe concede o direito à subjetividade, e à expressão íntima. De modo que as reflexões do Diário não surpreendem o leitor e são de certo modo esperadas: o leitor quer saber o que pensa e como sofre Ottilie. Será que, do ponto de vista do conteúdo, encontramos no Diário as marcas de um espírito de contestação e revolta, como em alguns romances franceses da época, nos quais falam as mulheres filósofas? ${ }^{2}$

Em As afinidades eletivas, encontramos no Diário diversidade de temas e modos de apresentação. Em nenhum deles há definitivamente revolta, ao contrário, chama a atenção o fato de que os fragmentos são, no geral, serenos, anti-sentimentais, não passionais; os diários exibem máximas morais, as quais sugerem relações entre moralidade e arte, aparência e essência, arte e natureza, natureza e costume, tempo e morte. Os dois primeiros diários são mais afetivos, há neles indícios de interioridade, Ottilie exprime opiniões que não puderam ser assumidas em público, diante dos amigos. O primeiro diário acompanha o contexto da restauração da capela da igreja, no qual o arquiteto e Charlotte

${ }^{2}$ Cf. Pierre Hartmann, La forme et le sens. Nouvelles etudes sur le roman des Lumières. Strasbourg: Presses universitaires de Strasbourg, 2009. Colas Duflo, Les aventures de Sophie. La philosophie dans le roman au XVIII siècle. Paris:CNRS Ėditions, 2013. 
discutem sobre o significado dos monumentos para a posteridade e Charlotte advoga um significado estético, racional, claro e evidente. Ora, Ottilie no Diário elidindo esse contexto, diverge sutilmente da opinião de Charlotte, ao sustentar que o significado de um lugar jamais é claro ou evidente, nem é o mesmo para todos, já que decorre de uma intuição subjetiva diante do objeto, a qual surge sempre cercada de certa opacidade. Nesse sentido, o significado dos objetos e monumentos perde universalidade, restringindo-se àqueles que ali viveram, amaram ou foram amados: "Há monumentos e sinais que nos aproximam daqueles que estão distantes ou já morreram" (Ibid., p. 169). A divergência exibida no Diário, não decorre de excesso de timidez ou respeito; ao contrário, exprime o modo peculiar de Ottilie observar a vida, sempre à distância e a possibilidade de, após a observação, acrescentar algo inesperado que não havia sido dito até então, por exemplo: o valor daquilo que é eternizado no futuro depende daquilo que é vivido no presente, daí que vida e morte se equivalem de tal modo que "por vezes, conversamos com alguém que está presente como se o fizéssemos com um retrato" (Ibid.).

No segundo momento do Diário, ainda mais subjetivo, o contexto é o da véspera do aniversário de Eduard. Ottilie sente saudade, teme nunca mais revê-lo; no entanto, nada é dito sobre isso, mas a falta é indiretamente transposta em imagens de fraturas e distanciamentos: entre a obra e o artista, os antigos e os modernos, ou, ainda entre as estações do ano. Por meio delas, Ottilie acolhe a mais radical das experiências de negação, a da possibilidade de não mais desejar. Nos três momentos seguintes, as anotações elidem o principal evento que é a visita de Luciana, filha de Charlotte, mas abordam temas ligados à sociabilidade, 
de modo que aqui temos as "sentenças e máximas" que são, nas palavras de Goethe, "referentes à vida ou dela extraídas". Mas o que se nota é que ainda aqui as sentenças não se referem diretamente à vida, ${ }^{3}$ os fragmentos são abrangentes e apenas sugerem direções de conduta ou conselhos sobre a vida em sociedade; nesse sentido, só funcionam como aforismos gerais sobre a vida, cuja validade como orientação para o agir decorre do arbítrio do leitor. Cito apenas três exemplos entre as máximas anotadas: "Toda palavra que proferimos suscita uma ideia contrária"; "Jamais nos distanciamos tanto do objeto de nossos desejos do que quando imaginamos possuí-lo"; ou ainda: "A arte ocupase daquilo que é difícil e bom." Por fim, no último trecho do diário, o sexto, temos novamente anotações afetivas transpostas em sentenças gerais, que, nesse caso, teriam sido retiradas de cartas de amigos, supostamente escritas por Eduard. Em tom de despedida, as sentenças relacionam vida e morte com a passagem do tempo, culminando em aforismos que aglutinam uma linguagem universal da sabedoria com entonações subjetivas: "Tudo aquilo que, à sua maneira, é perfeito deve exceder sua própria contingência, deve tornar-se outra coisa, tornar-se incomparável (...) uma vida sem amor, sem a proximidade do amado, é apenas uma comédie à tiroir, uma peça ruim, perdida entre os guardados (...)" (Ibid. p. 236).

Nessas sentenças e máximas a filosofia é reduzida a um certo bom senso, em um procedimento generalizante diante do qual a voz de Ottilie quase emudece. É verdade que as máximas foram escolhidas ou adotadas pela personagem e, nesse sentido,

\footnotetext{
3 Segundo Andreas Grimm, Goethe provoca os meios intelectuais, dominado pelo pano de fundo do Aufklärung tardio, ao recusar o método direto de observação da natureza e das paixões, sublinhando o acesso indireto à experiência. (Grimm, 2010, p. 138)
} 
denotam certa liberdade e autonomia do querer; no entanto, os conteúdos, ainda que abrangentes, distanciam-se de suas angústias individuais. Podemos afirmar, então, que elas não são o ponto de vista individual de Ottilie? Se o querer é aqui apenas formal, pois limitado aos conteúdos dados, pode-se, então, afirmar que as máximas se refiram a uma ordem pré-estabelecida, eternizada, com a qual a personagem deverá reconciliar-se fatalmente e da qual ela jamais conseguirá se libertar? Esboço uma resposta negativa, em três passos:

1. O Diário opera em primeiro lugar como sociabilidade. Em Goethe encontramos um uso da filosofia ainda ligado à sociabilidade, à conversação, entendida como prática de circulação de idéias, em um espaço público; na Máxima 190 lemos: "Um conjunto de anedotas e máximas é para o homem do mundo, o mais precioso tesouro se ele souber em conversação, distribuir as primeiras pelos momentos apropriados e se souber, por outro lado, lembrar-se das segundas em situações em que venha a encontrarse"(Goethe, 2001, p. 55). O homem público é chamado, assim, a manter a conversação, a opinar em público, daí a utilidade de um diário de máximas.

Nessa direção Gadamer sugere em "A naturalidade da linguagem em Goethe" que o modo como Goethe insere reflexões em suas narrativas não resulta de planos previamente concebidos, mas de procedimento, ao modo despreocupado, quase incidental ou ocasional, de conquistar a boa vontade do leitor e o livre acordo com ele; procedimentos, portanto, que deixam a abra aberta e não fechada. Desse modo, segundo Gadamer, Goethe pairava nas mais diversas esferas do conhecimento e da vida, buscando realizar essas passagens sempre ao modo natural, insinuando múltiplas possibilidades de interpretação e compreen- 
são (Gadamer, 2010, p. 260-261).

De fato, o Diário não visa persuadir ou convencer o leitor de nenhuma tese específica, mas nem por isso o que é dito deixa de ser relevante. Se os fragmentos se dirigem ao leitor, esperando dele adesão ou desacordo, é porque Goethe participa, aqui, da forte exigência do século XVIII de tornar o pensamento comunicável por meio de uma linguagem adequada. É a linguagem do Diário que permite essa partilha do pensamento; nele, o formato das máximas, ou conselhos sobre como se deve agir, reivindica universalidade; em outras palavras, por meio do Diário o leitor, até então passivo, torna-se ativo, no exato momento em que o que vai ser narrado precisa afastar-se da simples particularidade subjetiva. Daí a importância do Diário, por meio do qual o autor dá publicidade às reflexões de Ottilie. O tema da partilha dos pensamentos não é exclusivo de Goethe. Kant, por exemplo, assinala na Crítica da Razão Pura, que o que marca a diferença entre a convicção, que repousa em razões objetivas e a simples persuasão, que repousa em razões subjetivas, é o fato de algo poder ser comunicado, e que julgamentos estejam de acordo sobre o que foi dito. "A pedra de toque para decidir se o considerar-algo-verdadeiro é uma convicção ou um simples persuasão é, portanto, externamente, a possibilidade de comunicá-lo e de encontrá-lo válido para a razão de qualquer ser humano" (Kant, 1983, B 849).

2. Karl Solger, na carta a Tieck sobre As afinidades eletivas, de 1809, ao justificar no romance moderno a concisão da narração e as longas e frequentes passagens reflexivas, observa que as considerações e reflexões não são de fato filosóficas, no formato daquilo que é conhecido oficialmente como filosofia; não obstante, são reflexões que penetram profundamente naquilo que 
é essencial e significativo na vida cotidiana. "As reflexões são a verdadeira vida", os "elementos nos quais o singular respira"; daí serem reflexões intrínsecas às relações privadas. Eis a estrutura do romance moderno, diz ele, cujo melhor exemplo é o romance de Goethe, As afinidades eletivas: mesmo que o ponto de partida seja a natureza, as numerosas reflexões e observações referem-se ao exame da individualidade humana, ao caráter individual: "a arte do romance, conclui Solger, é a tentativa de reunir a individualidade humana ao gênero humano" (Solger, 2004, p. 181-188).

Goethe em conversa com Eckermann reconhece como a carta de Solger agradou-lhe muitíssimo ${ }^{4}$; a despeito do elogio, valeria a pena demarcar a tensão, apenas entrevista por Solger, entre individualidade e interioridade no romance. As máximas referem-se à vida cotidiana e nesse lugar expressa-se toda a personalidade social de Ottilie; paralelamente, sua interioridade vive reviravoltas violentas e permanece em profunda obscuridade. Walter Benjamin no decisivo ensaio sobre o romance de Goethe afirma a mesma zona de opacidade, de modo que, para ele, a clareza das máximas anotadas contrasta com a interioridade da jovem que é cada vez mais obscura, principalmente para ela; constatando, em decorrência do paradoxo, o silêncio moral da personagem e uma existência interior que permanece fechada para o leitor. "Somente em seu diário, afirma Benjamin, parece manifestar-se por fim a vida humana de Ottilie. Toda a sua existência dotada de linguagem deve ser procurada cada vez mais nesses mudos apontamentos. Contudo, também eles apenas constroem o monumento para aquela que morreu lenta-

4 Cf. Eckermann, Conversações com Goethe. Trad. Luis Silveira. Lisboa: Vega, s/d, pp. 150-151. 
mente"(Benjamim, 2009, p. 87). Definitivamente, diz Benjamin, eles surgem tarde demais, quando apenas prenunciam seu desaparecimento. De modo que o Diário não elimina o caos, nem a obscuridade das relações e intenções, nem impede a catástrofe que se aproxima.

De fato, na estrutura narrativa a subjetividade de Ottilie, como interioridade, permanece fechada; no entanto, inversamente, com o Diário abre-se outra porta para a subjetividade. O Diário não se volta à subjetividade diretamente, mas aos sentimentos de Ottilie mediados pelos dados exteriores e históricos; ou seja, a uma intimidade mais profunda, esteticamente figurada como nexos entre partes, isto é, como forma, ou ainda, como exterioridade íntima. Segundo Andreas Grimm, é por essa razão que é necessário examinar a formação das máximas no interior da obra; quando Goethe afirma que elas são referentes à vida ou dela extraídas, significa que elas não decorrem da observação direta da natureza, nem da expressão de uma sensação interna, mas de uma compreensão estética; dito de outro modo, trata-se de obter de um acontecimento único, a formalização de uma impressão subjetiva, que é uma abordagem não argumentativa, mas a apreensão narrativa que surpreende um certo sentimento. $^{5}$

Goethe, portanto, combinando as máximas com o fluxo da narrativa, compõe um tênue equilíbrio. O romance opera com

${ }^{5}$ Grimm observa o funcionamento da compreensão estética especificamente no episódio da narração da humilhação de Carlos I. "Ottilie não imita o gesto do rei, que de resto seria apenas arrogância, mas constrói ( Nachvollzug) sua atitude com base neste episódio". A máxima deixa de ser estática e ganha mobilidade, porque surge da situação narrada e não como um caso de argumentação racional: "Isso me pareceu tão doloroso - não sei se com razão - que desde aquele instante não posso ver cair algo das mãos de uma pessoa, sem abaixar-me para pegar." (Grimm, 2010, p. 143) 
a palavra oportuna por meio da qual o leitor é por assim dizer colocado diante de um modelo de reflexão por meio do qual pressente o sensato e o razoável. Isso porque as máximas não operam apenas com aquilo que já foi pensado, como mera constatação e repetição de uma ordem passada com a inevitabilidade de que as coisas sejam sempre assim, mas com o desafio de atualização da máxima pelo leitor diante da situação narrativa, isto é, como porvir, como provocação diante daquilo que pode ser observado mais uma vez na natureza; daí o sentido em copiar textos de outros tempos, já que a natureza é a mesma. Na Máxima 309, lemos que "é sempre o mesmo mundo que se abre à contemplação, que sempre é observado ou pressentido"(Goethe, 2001, p. 76). As anotações do Diário são, nesse sentido, "pensamentos recebidos", que são "recolhidos esteticamente", diz Grimm, como idéias que emergem da cultura geral; ao contrário, permitem à experiência do "leitor alargar-se ao infinito" (Grimm, 2010, p. 145).

3. Goethe não abandona a ambição filosófica, fazendo do romance, como Rousseau e Diderot, também um meio adequado à reflexão sobre a própria atividade do pensamento. Na linguagem da ficção encontramos a questão dos limites e possibilidades do conhecimento de modo geral e, sobretudo, o tema das paixões e de como nelas se pensa a relação entre a ideia e o efetuado; abstração e vida. De fato, contra uma filosofia que é mera abstração, Goethe sustenta o procedimento de composição no qual ideia e multiplicidade aparecem sempre juntas; em suas palavras, o "verdadeiro observador é aquele que pensa"(Goethe, 2001, p. 130). No entanto, não se deve passar imediatamente do fenômeno à explicação; ao contrário, é necessário evitar a precipitação e demorar-se na manifestação, isto é, no fenômeno, 
bloqueando "a tirania da ideia", como sustenta na Máxima 428: "as teorias resultam habitualmente da precipitação excessiva de um entendimento impaciente que gostaria de pôr de lado os fenômenos observáveis e, em seu lugar introduzir imagens, conceitos e até mesmo frequentemente palavras" (IdId., p. 101). Essa calma ao narrar permite, diz ele, "considerar-se constantemente o interior e o exterior como paralelos, ou, mais ainda, como entretecidos entre si. É o ininterrupto movimento de sístole e diástole, de inspirar e expirar, do ser vivo. Se não somos capazes de o exprimir, observemo-lo ao menos com rigor e prestemos-lhe a atenção" (IdId., p. 70). Desse modo, o tema teórico, adverte Goethe, nos papéis do espólio, deve ser introduzido na vida prática para que então tenham "validade para todo o mundo" (IdId., p. 233) Definitivamente, em Goethe observa-se a luta ferrenha contra a abstração: "a teoria, de um lado, e a experiência/fenômeno, do outro, estão em conflito permanente. Qualquer unificação no âmbito da reflexão é ilusória"; nesse sentido, "só através da ação podem ser unificados" (IdId.).

Nota-se na estrutura d'As afinidades eletivas um dinamismo que oscila entre estabilidade e variação, por meio do qual a narrativa avança em um ritmo interrompido, entre a normatividade das anotações do Diário e a flexibilidade das ações. Por meio dessa oscilação, Goethe intercala ideia (ideal) e fenômeno: a ideia compreendida como estrutura universal e o fenômeno como a realização radical dessa estrutura em uma individualidade própria; ou seja, a questão é a estrutura universal com a personalidade original de Otillie, isto é, com um fenômeno que é dinâmico e se manifesta no tempo. O problema formal do romance é, nesse sentido, filosófico, pois consiste em ver como o autor confere a essa individualidade irredutível, sua inscrição na 
universalidade; mesmo sabendo que no caso de Ottilie há pouca variação no seu caráter, sua personalidade não é de todo fixa, mas forma em formação, isto é, Bildung.

Para pensar a transposição dos planos na estrutura interna da obra, convém aproximar os procedimentos estéticos de Goethe da sua filosofia da natureza. Nos textos sobre a metamorfose das plantas, Goethe observa que a natureza também não é estática, haja vista que é dotada de uma potência de inventividade infinita; a natureza não é a arte, tampouco é um livro "escrito na linguagem da matemática", pois nela encontramos também o jogo de formas que se inventam. ${ }^{6}$ No Ensaio sobre a pintura de Diderot, de 1798, Goethe já esclarecia sobre a natureza espiritualizada: "Mas o que é o exterior de uma natureza orgânica, senão a aparição que eternamente se modifica do interior? Essa exterioridade, essa superfície está adaptada de tal maneira a uma estrutura interior múltipla, enredada e suave, que ela se torna, desse modo, ela mesma algo de interior, na medida em que ambas as determinações, a exterior e a interior, estão sempre na mais imediata relação, tanto na mais silenciosa existência quanto no mais forte movimento"(Goethe,2005, p. 159). É por essa razão que na concepção da planta primordial Goethe salienta o movimento de forças atuando a partir de um centro em direção às partes, movimento a partir do qual o todo pode ser intuído.

${ }^{6}$ Cf. Laurent van Eynde, La libre raison du phénomène. Essai sur le "Naturphilosophie de Goethe". Paris: Vrin, 1998. O autor sustenta que Goethe prefere utilizar o termo Bildung ao de Gestalt para falar das formas naturais, daí Goethe utilizar expressões como: "aventura da forma", "forma em movimento", "forma em formação": "Tais formas não se preservam em uma generalidade abstrata e desencarnada, mas são investidas necessariamente na contingência do sensível e no acontecimento" (p. 172). 
Além disso, Goethe sugere, também em sintonia com sua "filosofia da natureza", que o pensamento humano opera com a dinâmica da união e da divisão. Na Máxima 572 lemos: "A existência no seu todo é um eterno separar e ligar. Segue-se pois que os seres humanos, ao considerarem o gigantesco fenômeno, também se põem a separar e a ligar."'(Id., 2001, p. 129). Não há, no entanto, nenhuma hierarquia entre essas operações, como se ao final um todo imperceptivelmente recolhesse as partes e o quadro pudesse ser recomposto. Nesse sentido o romance As afinidades eletivas é exemplar desse procedimento de divisão no qual quando mais a singularidade se afirma mais se torna enriquecida a universalidade; ou seja, nos termos de Goethe, "a mais singular das ocorrências sempre se apresenta como imagem e semelhança do mais universal"( Ibid.). De modo que a história do desenvolvimento do indivíduo, o que seria a Bildung, é, neste caso a história da exacerbação da singularidade em diálogo constante com a universalidade. É no movimento de intensificação que a essência se apresenta em sua figura radicalmente original. Acompanhada pela normatividade das máximas e reflexões do Diário, a individualidade não é conduzida ou ordenada por elas, mas avança na tensão permanente em direção a sua irredutível singularidade, uma tensão na qual a individualidade confronta os seus limites, sem perder o horizonte de uma universalidade.

Cabe observar, nesse sentido, apenas de passagem, que o romance corrobora o sentido que as máximas adquirem no século XVIII. Em Kant, por exemplo, elas operam especialmente na filosofia prática como princípio prático subjetivo, isto é, como aquilo que determina o agir segundo as condições do sujeito. Se na Fundamentação da Metafísica dos costumes, as máximas estão diretamente ligadas ao agir moral, na medida em que a "má- 
xima é o principio subjetivo do querer" (Kant, 1980, p. 115), na Crítica da razão prática, Kant amplia a questão ao afirmar que "proposições fundamentais práticas são proposições que contêm uma determinação universal da vontade, determinação que tem sob si diversas regras práticas. Essas proposições são subjetivas ou máximas, se a condição for considerada pelo sujeito como válida somente para a vontade dele; mas elas são objetivas ou leis práticas, se a condição for conhecida como objetiva, isto é, como válida para a vontade de todo o ente racional" (Id., 2003, p. 65).

Há uma dialética complexa entre o universal e o particular no romance que interdita que a essência possa ser compreendida em uma universalidade fixa e abstrata; impedindo, igualmente, que a singularidade seja interpretada como uma resistência irredutível à universalidade. Trata-se de uma relação entre as partes e o todo, da qual resulta uma unidade estética única: a obra. Percorrer o movimento de tensão entre o singular e o universal, no entanto, não significa dominar o fenômeno, nem desvelar seu segredo, uma vez que "natureza só se manifesta em nós, balbuciando seu mistério", diz Goethe na Elegia de Marienbad, mas entrever uma presença íntima ao real, que chamei acima de um exterior íntimo. "A vista imediata dos fenômenos originais nos mergulha em um tipo de angústia, sentimos nossa insuficiência; a despeito disso, o jogo eterno do empírico nos alegra", diz Goethe (Goethe, 1999, p. 367).

Como se sabe, o poeta insiste, em vários textos, especialmente em $O$ ensaio sobre a pintura de Diderot, que arte não é natureza, mas rivaliza com ela, na medida em que produz um efeito diferente da natureza, pois se mantém na superfície dos fenômenos. Nos termos de As afinidades eletivas, manter-se na 
superfície significa que a obra se atém à apresentação de um excesso de vida, de um transbordamento, que é a pura aparência sensível, entendida como o aparecer de uma "superficialidade profunda", segundo Eugene Fink (1960, p. 228). Nesse aparecer de uma superficialidade profunda a questão do todo permanece esteticamente posta; estamos, portanto, diante de um discurso orientado na direção da universalidade, pois se a arte não é a natureza, ela é sua "intérprete mais digna"; a arte é conhecimento por meio do estudo de uma universalidade concreta e perceptível, já que a força do artista "consiste em intuir, apreender um todo significativo, em perceber as partes" (Goethe, 2005, p. 150).

Para expor algo difícil ou tornar visível algo monstruoso, no livre movimento do seu aparecer, sem excluir a dimensão lírica do aparecer, Goethe insiste em apontar no Diário como o sofrimento se transmuta em sabedoria, pois com base nas máximas o ver e o compreender integram-se, não como fusão absoluta, mas como desenvolvimento de linhas paralelas, que fogem em direção ao infinito. Em outros termos, a essência do ver pressupõe a percepção da diversidade e simultaneamente a tentativa de constituir uma totalidade, uma imagem geral. Em suas palavras, "ver a ideia com os olhos". E o que diz o narrador, nos termos precisos do capítulo oito d'As afinidades eletivas, na cena diante do caixão do padre e do berço da criança: "observar e refletir sobre o nascimento e a morte, o esquife e o berço, postos um ao lado do outro, e acolher essa oposição monstruosa não apenas com a imaginação, mas com os próprios olhos." ( $O p$. Cit., p. 230) Ora, Ottilie encarna esse procedimento literário e filosófico, haja vista ser dotada dessa qualidade fenomenológica de ver aquilo que aparece diante dela, não pela força da 
imaginação, mas pela manifestação, pela aparição da própria coisa. Nesse aparecer, esclarece Goethe, "não há nada de fantástico" (Phantastisches), mas o próprio natural nomeado, ou seja, a aparição narrada em seus mínimos detalhes, em posições diferentes, denotando uma relação profunda com as coisas.

Nesta estrutura narrativa, composta de partes visíveis, efetuase uma unidade, que é produzida pelo artista a partir da exacerbação da individualidade. Cada personalidade desenvolve ao aparecer - Ottilie, por exemplo - a imagem do mundo que é possível e necessária para ela; uma harmonia entre as partes se manifesta, dizendo aquilo que é conforme à natureza da obra ${ }^{7}$. O "efetivamente acontecido é contemplado com assombro" pelo leitor; não obstante, o evento manifesta-se organicamente articulado com o Diário, com as máximas do agir de Ottilie, livremente escolhidas por ela, como justaposição de camadas ou acumulação irregular de múltiplos elementos. Em outros termos, se cada máxima é atualizada por Ottilie, cabe igualmente ao leitor ativo apropriar-se desse campo de potencialidades que os fragmentos circunscrevem. De modo que a obra constitui-se na unificação desses elementos por meio dos quais um círculo é traçado entre criador, obra e leitor; a unidade, porém, não é síntese arbitrária, mas fluxo de energia; assim como a natureza é para Goethe fluxo vivo de energia em permanente transformação. Energias que provocam forças de percepção, de formação e de expressão. É nessa ordem de energias que reside a autonomia radical da obra, de modo que a palavra oportuna dos diários

${ }^{7}$ No prefácio da Doutrina das cores Goethe afirma: "expressar a essência de algo é propriamente um empreendimento inútil. (...) Em vão nos esforçamos por descrever o caráter de uma pessoa, mas basta reunir suas ações e feitos para que uma imagem (Bild) de seu caráter nos seja revelada"(Goethe, 1993, p. 35). 
não corrige, direciona ou altera a personalidade de Ottilie, mas acompanha o movimento de sua formação na ação, espraiandose nela, irradiando-se, acompanhando esse desenvolvimento em direção ao seu centro, em linhas centrípetas, à sua essência mais própria. Daí que na obra, como fluxo, bem como na natureza, não cabem conceitos unilaterais e abstratos, mas apenas máximas; antigas máximas que não estabilizam conceitos, mas reverberam nos leitores, acompanhando intensidades e metamorfoses; máximas que tem validade até para exceções, nas quais o inútil, o pernicioso, ou, sobretudo o destrutivo tem lugar. Como pode ser lido na Máxima 571: "Propriedades fundamentais de uma unidade viva: separa-se, unir-se, espraiar-se no universal, persistir no particular, transformar-se, especificar-se e -assim como aquilo que é vivo se pode manifestar sob milhares de condicionamentos - aparecer e desaparecer; solidificar-se e fundir-se; dilatar-se e contrair-se. Ora, como todos estes efeitos ocorrem simultaneamente, assim podem todos e cada um produzir-se ao mesmo tempo. Surgir e desvanecer-se, criar e anular, nascimento e morte, alegria e sofrimento, tudo opera por meio e através do outro, no mesmo sentido e na mesma medida. Por causa disso a mais singular das ocorrências sempre se apresenta como imagem e semelhança do mais universal." (Goethe, 2001, p. 129)

\section{Referências bibliográficas}

BENJAMIN, Walter, Ensaios Reunidos: escritos sobre Goethe. São Paulo: Duas Cidades/Editora 34, 2009.

BITTNER, Rüdiger, Máximas. In: Studia Kantiana, n ${ }^{\circ}$, 2004. 
DUFLO, Colas, Les aventures de Sophie. La philosophie dans Le Roman au XVIII siècle. Paris: CNRS Éditions, 2013.

. (org). Fictions de la pensée, pensée de la fiction. Roman et philosophie aux XVII e XVIII siècles. Paris: Hermann Éditeurs, 2013.

GOETHE, J.W. Die Wahlverwandtschaften, v.VI, Werke, Hamburger Ausgabe. München: C.H.Beck Verlag, 1981.

. As afinidades eletivas. Trad. Tercio Redondo. São Paulo: Penguin/Companhia das Letras, 2014.

Maximen und Reflexionen. Werke, Hamburger Ausgabe. v.12 München: C.B.Beck Verlag, 1999. Trad: Afonso Teixeira da Mota, Lisboa: Guimarães, 2001.

- Escritos sobre arte. Trad. Marco Aurélio Werle. São Paulo: Humanitas/Imprensa oficial, 2005.

. Doutrina das cores. São Paulo: Nova Alexandria, 1993. . Fausto. J. K. Sgall (trad.). São Paulo, Editora 34, 2007. . Maximen und Reflexionen. Werke, Hamburger Ausgabe. v.12 München: C.B.Beck Verlag, 1999. Trad: Afonso Teixeira da Mota, Lisboa: Guimarães, 2001.

- Doutrina das cores. São Paulo: Nova Alexandria, 1993.

VAN EYNDE, L. La libre raison du phénomène. Essai sur la 'naturphilosophie' de Goethe. Paris: VRIN, 1998.

GADAMER, Hans-Georg, Hermenêutica da obra de arte. São Paulo: Martins Fontes, 2010.

GRIMM, Andreas, "Auf das Leben bezügleiche und vom Lebem abgezogene Maximen. Beobachtungen zu Otillies Tagebuch". In: Helmut Hühn (org). Goethes Wahlvervandtschaften:Werk und Forschung. Berlin: De Gruyter, 2010.

HARTMANN, Pierre, La forme et le sens. Nouvelles études sur 
le roman des Lumières. Strasbourg: Presses universitaires de Strasbourg, 2009.

HERMANN, Elisabeth, Die Todesproblematik in Goethes Roman Die Wahlverwandtschaften. Berlim: Erich Schmidt Verlag, 1998.

SOGER, K.W.F. L'Art et la tragédie du beau. (org. Anne Baillot) Paris: Éditions Rue d'Ulm, 2004. 